\title{
AIDS researchers seek criteria for vaccines
}

\section{Erika Check, Washington}

Scientists have been seeking an AIDS vaccine for two decades now, with precious few signs of success. But while their search has focused primarily on a vaccine that would prevent the disease, some vaccine researchers have been looking for ways to augment existing drug treatments for AIDS.

Just as they find preliminary evidence that such a vaccine might work, however, researchers investigating such therapeutic vaccines are running into new difficulties.

Advocates of therapeutic vaccines complain, in particular, that regulators are stalling research in this field by refusing to set clear expectations for what such a vaccine needs to do. Without clear targets, scientists and companies say that they are reluctant to set up large, costly clinical trials.

But government officials counter that researchers are demanding too much guidance too soon - before they've even shown that such a vaccine could work. "I think there's been a hold-up on both sides," says Ben Cheng of the government-sponsored Forum for Collaborative HIV Research, which hosted a workshop on therapeutic vaccines in Washington DC on 23 and 24 April.

The idea behind therapeutic vaccines is to prolong the useful life of anti-retroviral therapies, which allow many patients to survive AIDS but are prone to failure over time, as the virus evolves resistance to the drugs. A few studies have hinted that a therapeutic vaccine could help to solve this problem by allowing patients to take short breaks from treatment.

In one such study, funded by the ANRS,

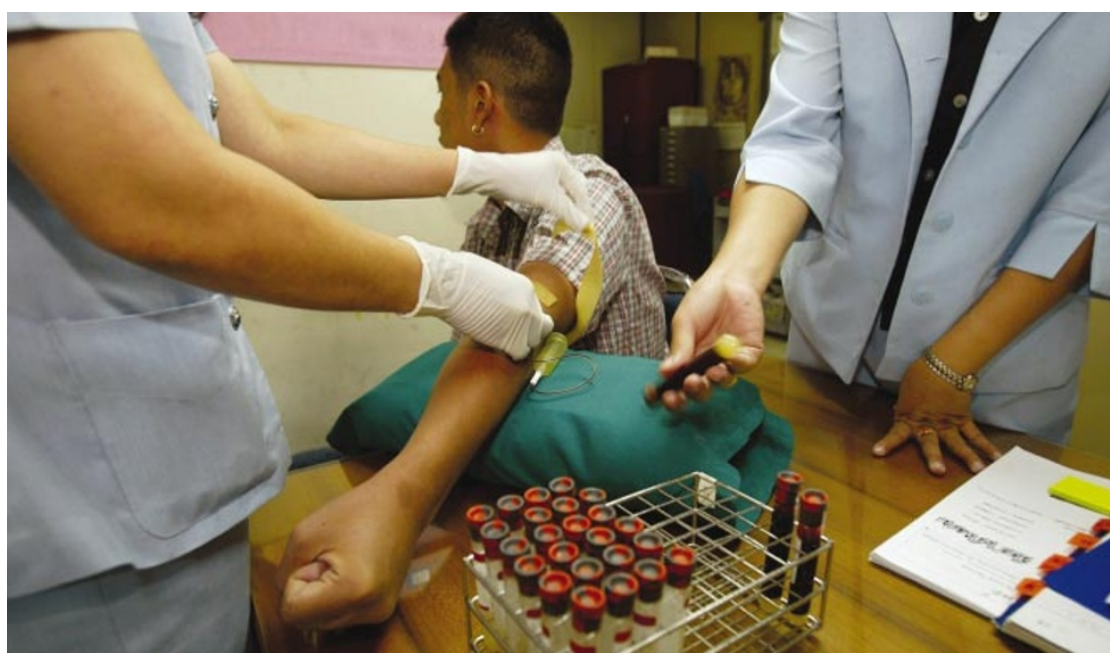

At the sharp end: researchers seek therapeutic vaccines to treat AIDS, as well as preventative ones.

the French national AIDS-research agency, Brigitte Autran and Christine Katlama of the Hôpital Pitié-Salpêtrière in Paris found that a canarypox vaccine let some patients take slightly longer breaks from drugs than others (see Nature 422, 650; 2003). And earlier this year, Yves Levy of the ANRS reported that patients who took a vaccine and a biological booster suppressed the virus better than those who did not take a vaccine.

The question now is what regulatory agencies will do with this evidence. A preventative AIDS vaccine succeeds when it stops people becoming infected with the virus. But a therapeutic vaccine's success could take many forms: reducing the number breathing. When researchers dribble some isopropyl alcohol onto one of the yeast cells, the pitch increases sharply, as if the cell is emitting a shrill cry. A dead cell produces the kind of static you might hear when tuning a radio.

Researchers have previously used an AFM to detect the pulsing surface of cardiac cells, which 'beat' even when removed from the body (S. G. Shroff, D. R. Saner and R. Lal, Am. J. Physiol. Cell Physiol. 269, C286-C292; 1995). But Gimzewski thinks that he's the first to listen to the membrane resonance of other cell types.

Gimzewski - a high-flyer at IBM who has published frequently in major scientific journals, including Nature - hasn't yet published anything on his idea. But he has discussed it with the LA Weekly, an alternative newspaper in Los Angeles, and he plans to demonstrate it this autumn at the Los Angeles County Museum of Art, in a nanotechnology exhibition held jointly with an artist with whom he has collaborated before, Victoria Vesna. He says that this approach fits in with his goal of taking science to a wider audience.

Sceptics point out that the technique may not work for mammalian cells, which have much softer membranes than yeast cells. But Jan Hoh, a physiologist at Johns Hopkins School of Medicine, says that he is intrigued by the concept of sonocytology. "If there are frequencies in the kilohertz range that truly are diagnostic to something going on in the cell, that would be interesting," says Hoh. He cautions that treating cells with alcohol is too crude to reveal much, however. of HIV particles in a patient's body, for example, or allowing the patient to stay off drugs for a certain period of time.

So far, the US Food and Drug Administration (FDA) and other agencies have not told scientists which of these criteria it will consider as proof of success. But at the workshop, Carol Weiss, a scientist at the FDA's Office of Vaccines Research and Review, gave some indications. "The treatment needs to change a patient's outcome in a clinically meaningful way," Weiss said, adding that the change must be "durable". How durable, she said, has not yet been determined, but she hinted that any approved vaccine would have to work for at least six months. Weiss also said that an FDA advisory committee would probably have to approve the first large trial of any therapeutic vaccine.

That statement will not satisfy everyone. But Dan Kuritzkes, director of AIDS research at the Partners AIDS Research Center at Massachusetts General Hospital, says that the FDA's comments will help scientists. "I think we came out with a much clearer sense of what the potential indications might be for therapeutic vaccines," such as a lower viral load or an extended time off treatment, Kuritzkes says. He adds that this is especially important for commercial vaccine development: "Industry needs to have a sense that if they get to the end of the road, the agencies will have similar expectations about what is reasonable."

Alan Landay, an immunologist at RushPresbyterian-St Luke's Medical Center in Chicago, says that the workshop marked a milestone for therapeutic vaccines in at least one sense: by the end of it, much of the tension between regulators and scientists had dissipated. "Everyone in the room saw that others were facing the same sorts of questions they had," Landay says. "Now we all know we're not alone in this quest." 